\title{
DIREITO DOS DESASTRES SOB O ENFOQUE JUS-AGRARISTA PARA UM DESENVOLVIMENTO BIOTECNOLÓGICO SUSTENTÁVEL
}

\section{LAW OF DISASTER IN FOCUS JUS-AGRARIAN FOR BIOTECHNOLOGICAL SUSTAINABLE DEVELOPMENT}

\section{RESUMO}

${ }^{1}$ Arthur Ramos do Nascimento

Os riscos do desenvolvimento biotecnológico são questões de proporções maiores do que se acredita e que igualmente recebem pouca atenção do Direito. O risco, como uma potencialidade, aparenta ser de pequena relevância quando comparado às vantagens circundantes ao desenvolvimento. A inexistência de discussões intensas a esse respeito acaba se mostrando preocupante, especialmente quando o avanço biotecnológico alcança dimensões desconhecidas. O presente trabalho apresenta uma análise interdisciplinar entre ramos do Direito apontando como a valorização do Direito Agrário e sua interação com o Direito dos Desastres pode ser realmente intensificadora e promotora de um Desenvolvimento Sustentável. A pesquisa traz considerações sobre como a busca pelo desenvolvimento de tecnologias, que podem combater a fome endêmica, serve como motivação positiva e, ao mesmo tempo, mercadológica do Capital. A conclusão, sempre em construção, aponta pela necessidade de publicização e intensificação dos debates jusagraristas dentro do Direito dos Desastres, especialmente no que tange aos desastres biotecnológicos. Observa-se que o Direito Agrário tem importantes contribuições para o Direito dos Desastres e, ambos, para a construção de um desenvolvimento biotecnológicos sustentável.

Palavras-chave: Direito agrário, Direito dos desastres, Biotecnologia, Desenvolvimento

\begin{abstract}
The risks of biotechnology development are higher proportions of issues than is believed and that proportionately receive little attention from the law. The risk, as a potentiality, appears to be of little concern when compared to the surrounding advantages. The absence of intense discussions in this regard turns out to be disturbing, especially when the biotechnological advances reaches unknown dimensions. This paper presents an interdisciplinary analysis of Law branches pointing to the appreciation of the Agricultural Law and its interaction with the Law of Disasters can be really enhancing and promoting a sustainable development. The research brings considerations about the search for the development of technologies that can combat endemic hunger serves as positive motivation and at the same time, market the Capital. The conclusion, always under construction, points out the need for publicity and intensification of jus-agraristas debates within the Law of Disasters, especially when it comes to biotech disasters. It is observed that the Agrarian Law has important contributions to the Law of Disasters and both, to build a sustainable biotechnology development.
\end{abstract}

Keywords: Agricultural law, Law of disasters, Biotechnology, Development

\footnotetext{
${ }^{1}$ Mestre em Direito Agrário pela Universidade Federal de Goiás - UFG, Goiás (Brasil). Pesquisador e professor magistério superior (efetivo) da Universidade Federal da Grande Dourados - UFGD, Mato Grosso do Sul (Brasil). Email: arthurramosdonascimento.adv@ @otmail.com
} 


\section{INTRODUÇÃO}

A percepção da realidade e dos problemas contemporâneos tem dotado o Direito da possibilidade de contínua releitura e reinterpretação. Por vezes, essa busca acaba ressaltando a amplitude de seus horizontes inter e transdisciplinares, como também reforçando a necessária observação de que os diversos ramos do próprio Direito devem caminhar de forma dialogada. A principal função desse sistema de normas, princípios e institutos é influenciar a forma como o Estado e a sociedade irão se portar (e enfrentar) as situações complexas da vida. Essas acabam sendo melhor abordadas (ou se poderia dizer que recebem mais destaque) por meio de lentes específicas das esferas jurídicas especializadas (disciplinaridade). Entretanto, como o Direito é um todo unitário, é preciso ponderar que institutos tradicionalmente aplicados e estudados por um determinado ramo jurídico pode, e às vezes deve, ser também estudado por outras searas jurídicas de modo a alcançar o máximo de suas potencialidades.

O instituto do Direito dos Desastres se coloca na realidade e no mundo jurídico como um aspecto ainda pouco conhecido do Direito. A regulação sobre os efeitos dos desastres (e o gerenciamento dos riscos) tem ganhado mais espaço nos debates jurídicos, dado a acentuada modificação climática, mas também por força do desenvolvimento da Biotecnologia. Esse campo ainda relativamente desconhecido atua sobre possibilidades ainda mal compreendidas e que necessitam de uma adequada apreciação jurídica para amenizar as consequências dos (possíveis) desastres, visto se tratar de vidas humanas em jogo, da dignidade da pessoa humana, a segurança alimentar (e soberania alimentar), aspectos da ética do desenvolvimento entre outros. Não raro se pensa tratar de um problema meramente ambientalista, sendo importante quebrar essa concepção por força do Direito dos Desastres também enriquecer os debates agraristas, como se observará no presente trabalho.

Feitas as considerações, a proposta deste trabalho é responder (ou ao menos pontuar) o que é o Direito dos Desastres e qual é a sua importância? O Direito Agrário pode contribuir e ser beneficiado pelo Direito dos Desastres? Qual é o protagonismo da Biotecnologia na seara do Direito dos Desastres? É possível que o diálogo entre esses enfoques possibilite a construção de um Direito dos Desastres Biotecnológicos, com as contribuições do Direito Agrário para um Desenvolvimento Biotecnológico Sustentável? 
De modo geral, pretende-se apresentar uma nova possibilidade de interpretação do Direito a luz dos Direitos Humanos e dos direitos sociais, com aportes agraristas e dos avanços biotecnológicos. Destacadamente, anseia-se desenvolver uma solução com as contribuições do Direito Agrário para o problema de eventuais desastres biotecnológicos, cada vez mais possíveis em razão do desenvolvimento de tecnologias para a produção de alimentos.

Justifica-se a escolha do tema em razão de uma preocupação científica e prática do Direito com a valorização do Direito Agrário. Os jus pensadores devem encontrar e desenvolver mecanismos de compreensão e regulação dos desastres biotecnológicos, onde tudo depende de um alcance acessível e fácil do problema.

Optou-se pelas pesquisas bibliográfica de diversos autores que pudessem, de alguma forma, colaborar com o amadurecimento (ainda não concluído) desse raciocínio jurídico. Não se pretende abarcar a matéria de forma exaustiva, vez que, pela sua abrangência, melhor seria abordada em uma tese de doutoramento (que é, inclusive, uma das pretensões futuras do pesquisador, de forma que esse ensaio se mostra um texto inicial para uma possível tese nesse sentido). A importância da matéria, contudo, nos impulsiona a, pelo menos, pontuar alguns fatos e argumentos que podem ser utilizados como fundamentos para uma compreensão mais humana do problema, abrindo, talvez, um novo leque de possibilidades para discussão.

O resultado que agora se apresenta dividiu-se em fases específicas da pesquisa, o que se traduz nos tópicos que se seguem. Inicialmente aborda-se o Direito dos Desastres apresentando conceitos elementares de sua pertinência para o contexto atual. Passa-se posteriormente a reforçar a importância de se fortalecer os debates jusagraristas como área estratégica para o desenvolvimento (acadêmico, humano e econômico). Superadas tais abordagens o artigo se dedica a tecer algumas considerações sobre a soberania alimentar e a segurança alimentar, como problemas a serem resolvidos e, então, a utilização da Biotecnologia como instrumento para o alcance das destacadas necessidades humanas. Por fim são tecidas as considerações finais, apontando como o Direito dos Desastres se envolve de importância para os debates jusagraristas, especialmente quando pensamos nos riscos do uso da biotecnologia sem o devido aporte regulamentar/normativo e a ética para um desenvolvimento sustentável. 


\section{DIREITO DOS DESASTRES, CONCEITO E IMPORTÂNCIA}

Com a contínua e importante ampliação da discussão sobre a tutela integral dos Direitos Humanos, se potencializa a valorização do Direito dos Desastres. A preocupação quanto a desastres e seus danos têm ganhado mais espaços dentro dos debates jurídicos, pois os efeitos dos desastres, como assinala Fernanda de Salles Cavedon, "podem afetar de maneira diferenciada grupos, indivíduos e comunidades em razão de sua vulnerabilidade ambiental". Ainda, nesse aspecto a exposição a riscos e efeitos dos desastres deve ser entendida "como uma situação de violação de direitos humanos (...) especialmente o direito à vida" (CAVEDON; VIEIRA, 2012, p.118). Reforça-se ainda sua contribuição à garantia dos direitos humanos em função de sua dimensão coletiva.

É possível mesmo a compreensão que o entendimento dos desastres (naturais ou não) faz parte do necessário processo de superação da crise da civilização (na perspectiva da cultura ocidental, da economia globalizada, da racionalidade da modernidade). O mesmo pode se dizer da superação da crise do conhecimento e seus impactos (catástrofes industriais, bem como dos frutos da tecnologia e engenharia) sobre a natureza e a própria sociedade (DAMACENA, 2012, p.8). Vive-se um momento especial de conquistas por novos conhecimentos, época propícia para quebra de paradigmas.

Por desastres pode-se entender como sendo o evento (ou situação) que rompe os limites de danos locais (ou capacidade local de gestão de seus efeitos), gerando a necessidade de assistência nacional ou internacional. Esse evento (ou situação) é, em geral, imprevisto, repentino e provoca um dano considerável, causando destruição e sofrimento humano (CRED apud SANTOS, 2014, p.357). Entende-se assim que é todo e qualquer acontecimento que configure como uma calamidade pública, ocorrendo normalmente de súbito e provocando danos e prejuízos consideráveis. O conceito comporta, como se observa, tanto acidentes naturais quanto humanos (dos quais destacamos os acidentes biotecnológicos).

De forma singela, temos que os desastres ambientais, consistem nas ocorrências (ou eventos) provocados por causas naturais, humanas ou mistas que resultem em comprometimento das funções ambientais, lesando interesses humanos, e 
incorrendo em alguma mudança ambiental. Ao lesar interesses humanos, como se observa, os desastres passam a ter relevância jurídica, devendo ser tratados pelo Direito.

Maurício Duarte dos Santos aponta o conceito trazido pela Organização Meteorológica Mundial (OMM) define os desastres naturais como

fenômenos meteorológicos e climáticos extremos que se produzem por causas naturais em qualquer lugar do mundo ou quando existem regiões mais vulneráveis que outras. Estes fenômenos constituem desastres naturais quando ocasionam a destruição de vidas e de meios de subsistência entre a população (2014, p.356).

Utilizando de uma conceituação legal, temos o Decreto n.7.257 de 4 de agosto de $2010^{1}$, que define desastre como: "desastre: resultado de eventos adversos, naturais ou provocados pelo homem sobre um ecossistema vulnerável, causando danos humanos, materiais ou ambientais e conseqüentes prejuízos econômicos e sociais" (Art. $2^{\circ}$, II).

Cabe observar que não é qualquer situação provocadora de dano passível de ser classificada como desastre. A Cruz Vermelha estabelece alguns critérios para considerar um evento como "desastre", devendo atender um ou mais: a) dez ou mais pessoas declaradas mortas (a morte pode ser presumida ou declarada por desaparecimento); b) cem ou mais pessoas declaradas afetadas pelo evento; c) declaração de estado de emergência; e, d) convocação de assistência internacional (CRED, 2012).

Como destaca Fernanda Dalla Libera Damacena, o estudo sobre os desastres (e suas várias modalidades) é difícil, ao mesmo tempo em que é extremamente relevante seu conhecimento científico para o Direito contemporâneo, que deve se preocupar com a "solidariedade intergeracional, sensitividade ecológica e com a responsabilidade de longa duração" (2012, p.9)².

\footnotetext{
${ }^{1}$ O referido decreto "Regulamenta a Medida Provisória no 494 de 2 de julho de 2010, para dispor sobre o Sistema Nacional de Defesa Civil - SINDEC, sobre o reconhecimento de situação de emergência e estado de calamidade pública, sobre as transferências de recursos para ações de socorro, assistência às vítimas, restabelecimento de serviços essenciais e reconstrução nas áreas atingidas por desastre, e dá outras providências."

${ }^{2}$ A responsabilidade de longa duração se mostra especialmente importante para o Direito dos Desastres Biotecnológicos em razão dos riscos e consequências poderem se desdobrar por gerações.
} 
No sentido de que é função do Direito acompanhar os acontecimentos sociais, regulando normas costumeiras ou positivadas, buscando o equilíbrio entre interesses (de natureza pública, privada, difusa etc.) há um campo vasto de atuação a ser considerado. As situações que envolvem os desastres não devem ser encaradas diferentemente (SANTOS, 2014, p.351). É preciso entender o que são os desastres e como seus efeitos (e até mesmo a precaução) é matéria da seara jurídica.

A definição do Direito dos Desastres não se apresenta como uma empresa fácil, revelando-se "ponto complexo estabelecer um conceito, já que o desastre pode ser entendido a partir de diferentes perspectivas, sejam elas social, ambiental, econômica,etc" (CAVEDON; VIEIRA, 2012, p.118). Como já destacado nem toda situação de dano não previsto pode ser classificado como desastre.

O Direito dos Desastres é um ramo do conhecimento jurídico relativamente recente $^{3}$, convencionalmente ligado ao Direito Ambiental ${ }^{4}$. Nasceu de uma preocupação de gestar e discutir estratégias a respeito do gerenciamento dos desastres, naturais, humanos e, como abordaremos com maior destaque, os desastres biotecnológicos.

Assim é preciso compreender, como destacado por Maurício Duarte dos Santos, que

tanto no plano internacional como no nacional, a ocorrência de desastres tem sido observada como sendo cada vez mais catastrófica, surge a necessidade não somente de se organizar a intervenção estatal na reparação do cenário pós-desastre, mas especialmente de reconsiderar juridicamente a questão da prevenção, do que é a gestão de riscos pressuposto. (2014, p.350)

Como destacado os desastres ambientais são o grande cerne da discussão do Direito dos Desastres. Entretanto, esse novo ramo especializado precisa também estar atento aos desastres tecnológicos e, especialmente, biotecnológicos. O Direito Brasileiro apesar de apresentar "predominância de riscos naturais, de forma alguma se pode desconsiderar a potencialidade crescente dos riscos tecnológicos e nucleares no Brasil"

\footnotetext{
${ }^{3}$ Pode-se dizer que surgiu nas últimas décadas do Séc. XX.

${ }^{4}$ O Prof. Maurício Duarte dos Santos chega a afirmar que existe uma "ligação umbilical com o Direito Ambiental".
} 
(TABAK, 2010, n.p). Em momento futuro dessa pesquisa se abordará especificamente sobre a potencialidade e dimensão dos desastres biotecnológicos.

O desenvolvimento da biotecnologia tem se voltado, em grande parte, para a melhoria da vida humana. Com destaque, se observa que há fortes investimentos para o desenvolvimento biotecnológico para o agronegócio, na produção de alimentos, agrotóxicos etc.. No Brasil essa questão merece especial atenção, visto ser um país de vocação agrícola e que tem na produção alimentar um de seus maiores potenciais. Nesse sentido, o fortalecimento do Direito Agrário se faz mister importante já que é o ramo do Direito que melhor regula o espaço agrário, contribuindo para um desenvolvimento sustentável (especialmente atento para os debates biotecnológicos).

\section{A IMPORTÂNCIA DO FORTALECIMENTO DO DEBATE JUS AGRARISTAS NO CENÁRIO NACIONAL}

Como um ramo relativamente recente no Direito nacional ${ }^{5}$, o Direito Agrário desponta como seara jurídica particularmente relevante. O Brasil é um país de forte influência rural, dada sua história, e também de forte vocação agropecuária. Urge compreender a especificidade do Direito Agrário nesse contexto e, por certo, a conceituação desse campo jurídico se faz assaz importante.

Por Direito Agrário podemos entender "o conjunto de princípios e normas de direito público e de direito privado que visa disciplinar as relações emergentes da atividade agrária, com base na função social da propriedade" (CASSETTARI, 2012, p.5). No entendimento de Paulo Torminn Borges "é o conjunto sistemático de normas jurídicas que visam disciplinar as relações do homem com a terra, tendo em vista o progresso social e econômico do rurícola e o enriquecimento da comunidade" (1987, p.17). Para Fernando Pereira Sodero "é o conjunto de princípios e de normas, de Direito Público e de Direito Privado, que visa a disciplinar as relações emergentes da atividade rural, com base na função social da terra" (1968, p.32).

\footnotetext{
${ }^{5}$ Pode-se de dizer que ocorreu apenas com a Emenda Constitucional de 1964 à Constituição de 1946, onde consta a inclusão da desapropriação para fins de reforma agrária no texto constitucional. Em 1964 também regulamentou-se o Direito Agrário com o Estatuto da Terra (Lei n.4.504/64).
} 
Como assevera Benedito Ferreira Marques, citando Augusto Zenun, o Direito Agrário deve ser entendido em uma perspectiva ainda mais ampla que a simples relação do homem com a terra, pois "exige algo mais do que isso" importante especialmente no “desempenho da função social da propriedade, ou seja, o exercício da produção racional e econômica, visando chegar à empresa rural pelo que, com esse fator dinâmico, acrescido aquele estático, podemos afirmar ser a terra o objeto do Direito Agrário" (2012, p.5).

O Direito Agrário, nessa perspectiva, merece destaque por gestar aspectos do biodesenvolvimento e também da crise alimentar que se configura como uma preocupação (talvez crise) global. Assim destaca-se que:

"As crises mundiais recentes revelam uma vulnerabilidade do sistema agroalimentar em sua missão de oferecer alimentos em quantidade e qualidade para a população mundial. Em última análise, a satisfação das necessidades alimentares da humanidade está longe de ser concretizada. Deste modo, este artigo apresenta uma interpretação sobre as diferentes posições no campo de debate em torno da agricultura e alimentação, realçando as críticas e insatisfações diante de ambivalências da noção de segurança alimentar." (MORUZZI MARQUES, 2010, p.79)

O Direito Agrário desponta como um ramo de vanguarda desde sua origem por sempre preconizar a função social da propriedade, sendo o primeiro ramo jurídico a mencionar claramente o termo ${ }^{6}$, além de ser também seu elemento central (CASSETTARI, 2012, p.6-7). O Direito jus agrarista, assim, se apresenta como ramo estratégico para o desenvolvimento nacional, bem como, para garantir segurança com relação à crise alimentar e, também, como cenário para o desenvolvimento biotecnológico sustentável.

Como já assinalado, o Direito dos Desastres nasce de uma umbilical ligação com o Direito Ambiental, mas é preciso ponderar que sua pertinência torna necessária

\footnotetext{
${ }^{6}$ No Brasil o primeiro diploma legal a tratar do assunto foi o Estatuto da Terra. No contexto mundial a origem da função social "se deu com a Constituição mexicana de 1917 e a Constituição alemã de Weimar em 1919” (CASSETTARI, 2012, p.7).
} 
sua autonomia ou, dito de forma menos arriscada, torna necessária a sua ampliação para dialogar com outros ramos do Direito, especialmente o Direito Agrário que é um ramo próximo. Afirma-se tal necessidade, visto que

“o desastre ecológico pode ter como causa estritamente a ação humana, decorrente do desenvolvimento de atividades e tecnologias ditas perigosas e que envolvem um certo nível de risco; ou ser produto de fenômenos naturais, nos quais também incidem fatores humanos, a exemplo do agravamento de fenômenos climáticos decorrentes do aquecimento global, em grande medida provocado pela ação humana. Em muitos documentos originados de organismos internacionais se verifica a predominância da referência a desastres naturais, em detrimento dos tecnológicos, mas é importante ressaltar que intrínseco à concepção de desastre natural estão as ações humanas que contribuem ou intensificam os efeitos do desastre" (CAVEDON; VIEIRA, 2012, p.118).

Vive-se uma realidade de multicontextos e atualização de sentidos e significados. O Direito dos Desastres, como um ramo ainda relativamente novo, deve aproveitar desse momento de alargamento dos debates para sua própria consolidação e aplicação. O Direito Agrário, por sua vez, tem como principal elemento a busca pela Justiça Social. Não haveria Justiça, nem atendimento aos princípios mais caros ao Direito Agrário, se os desastres (especialmente os biotecnológicos) não fossem devidamente regulados e, quando possíveis, evitados ${ }^{7}$. Como assevera Fernanda Damaceno:

$$
\begin{aligned}
& \text { "partindo-se da noção de desastre como algo que ocorre no } \\
& \text { interior de uma sociedade de multicontextos, pretende-se } \\
& \text { estabelecer um sentido para o que se possa, talvez num futuro } \\
& \text { próximo, denominar de Governança e Direito dos Desastres. }
\end{aligned}
$$

\footnotetext{
${ }^{7}$ São, entre outros, princípios do Direito Agrário, que: I - a propriedade da terra é garantida, mas condicionada ao cumprimento da função social; II - Dicotomia: compreendendo a política de reforma (Reforma Agrária) e política de desenvolvimento (Política Agrícola); III - Combate à exploração predatória e aos mercenários da terra (e pode-se dizer dos recursos naturais); IV - o fortalecimento da empresa agrária; V - a proteção do trabalhador rural; VI - conservação e a preservação dos recursos naturais e a proteção do meio ambiente (MARQUES, 2012, p.17-18).
} 
Afinal, 'os chamados novos direitos exigem igualmente novas formas de observação/operacionalização dos sentidos na sociedade' e as organizações ocupam destacado papel na atualização desses sentidos. Como fenômenos multicomplexos, os desastres requerem uma resposta do Direito que permita a assimilação dos riscos, que privilegie o antropocentrismo alargado e uma 'epistemologia da complexidade'.” (p.92)

O Direito Agrário surge sob o signo da complexidade, como se observa, podendo comportar também uma análise fortalecida dos desastres (especialmente os não naturais). O ramo em análise tem enorme valor pois é dotado de uma "destinação universal, dirigida à comunidade e à sociedade, enquanto as demais [regras] têm apenas um dimensionamento social, familiar ou profissional" (GISCHKOW, 1988, apud MARQUES, 2012, p.18).

O ramo jus agrarista é vanguardista no sentido em que rompe com a lógica individualista dos ramos tradicionalmente ligados com a propriedade ${ }^{8}$. Nele se encontra a lógica fraternalista de uma visão global e social das ações e dos direitos, numa perspectiva de coletiva responsabilidade e distribuição de resultados. A função social, corolário desse direito, "é o centro em torno do qual gravita toda a doutrina do Direito Agrário" (MARQUES, 2012, p.33), bem como ganhou dimensão constitucional e prestígio reconhecido na doutrina (MARQUES, 2012, p.34).

Como a produção de alimentos está intrinsecamente ligado com o Direito Agrário, é importante oferecer alguns aspectos conceituais para melhor compreensão da proposta analisada nesse trabalho.

Essa preocupação ampla do Direito Agrário permite (ou lhe incumbe) analisar aspectos relacionados a demandas mundiais. A produção de alimentos e o combate a fome se mostram preocupações presentes nas pautas principais na Ordem Internacional. A discussão a respeito da "segurança alimentar" tem início com o fim da Primeira Guerra Mundial, marcando o início da utilização da expressão. A experiência da Guerra dotou a alimentação de significado estratégico, ligado diretamente à ideia da segurança

\footnotetext{
8 De forma equivocada o Direito Agrário é muitas vezes associados como um sub-ramo do Direito Civil, o que deve provocar estranheza. O Direito Agrário é um ramo completamente autônomo, dotado de legislação, princípios, lógica científica etc., o que the confere autonomia plena. Também há que se destacar que o Direito Agrário é sempre identificado como um ramo do Direito Privado, o que não é propriamente verdade, visto que está calcado também na lógica do Direito Público. Para saber mais ler Direito Agrário Brasileiro, de Benedito Ferreira Marques (2012, p.1-20).
} 
nacional, posto que a soberania nacional estaria, por sua vez, diretamente ligada à capacidade de autossuficiência no planto alimentar (FRITZ; FRITZ FILHO, 2011, p.42).

Essa preocupação alimentar resultou, também, na chamada Revolução Verde ${ }^{9}$, que difundiu a lógica de que se houvesse um significativo aumento da produção agrícola, acabaria com o flagelo da fome e da subnutrição (o que justificaria a adoção da produção monocultora e emprego intenso de insumos químicos).

Nesse sentido cabe compreender que a segurança alimentar "se dá pela estabilidade no país da produção de alimentos para a população, sem necessidade de importação, que irá estabelecer uma proteção à agricultura" (CASSETTARI, 2012, p.6). A segurança alimentar é um fator de direitos humanos por atender a ideia de direito ao alimento, enquanto a soberania alimentar está ligada à ideia do desenvolvimento (econômico, humano e cultural).

Por soberania alimentar, podemos entender como sendo

"o direito dos povos de definir usa próprias política e estratégias sustentáveis de produção, distribuição e consumo de alimentos que garantam o direito a alimentação para toda a população com base na pequena e média produção, respeitando suas próprias culturas e a diversidade de modos camponeses, pesqueiros e indígenas de produção agropecuário, de comercialização e de gestão dos espaços rurais, nos quais a mulher desempenha um papel fundamental. A soberania alimentar favorece a soberania econômica, política e cultural dos povos. Defender a soberania alimentar é reconhecer uma agricultura com camponeses, indígenas e comunidades pesqueiras, vinculadas ao território; prioritariamente orientada a satisfação das necessidades dos mercados locais e nacionais.(...)" (CAMPOS, 2006, p.154-155)

O direito a se alimentar se torna cada vez mais claro dentro do contexto dos direitos humanos, bem como a valorização cultural dos alimentos produzidos.

\footnotetext{
${ }^{9}$ A análise detalhada do contexto da Revolução Verde não é o foco do presente artigo. Assim, para aprofundamento no tema, sugere-se a leitura de "Muito além da tecnologia: os impactos da Revolução Verde" de Carolina Octaviano (2010).
} 


\section{AS CONTRIBUIÇÕES DA BIOTECNOLOGIA PARA O}

\section{DESENVOLVIMENTO}

As necessidades crescentes por alimento, como já apontado, impõe a utilização de novas e diferenciadas técnicas para obtenção de produtos em quantidade e qualidade suficientes. Nesse sentido se faz cada vez mais importante investir (financeira e juridicamente, se destaque) na biotecnologia ${ }^{10}$. Em uma singela síntese, a biotecnologia "pode ser compreendida como o ramo da tecnologia que se ocupa da aplicação de dados da engenharia e da biologia aos problemas decorrentes do relacionamento do homem com o ambiente que o cerca" (PENNA; CANOLA, 2009, p.75). Também pode-se entender que

Biotecnologia significa qualquer aplicação tecnológica que utiliza sistemas biológicos, organismos vivos, ou seus derivados, para fabricar ou modificar produtos ou processos para utilização específica. Trata-se de uma importante ferramenta tecnológica baseada na manipulação das menores estruturas que compõem os seres vivos. (SILVA, 2014, p.795)

Em função da busca pela soberania alimentar e da segurança alimentar houve diversos investimentos na biotecnologia como forma de suprir a demanda crescente. Karen B. B. Fritz e Luiz Fernando Fritz Filho, citando Mazoyer e Roudart, indicam que desde o fim da Segunda Grande Guerra centros internacionais de investigação agrícola (em sua maioria com financiamentos de fundações americanas e europeias) passaram a selecionar variedades alimentares (arroz, trigo, milho e soja, escolhidas pelo seu alto rendimento) adaptando, em estações experimentais, métodos novos e específicos de cultivo, disseminando-os (variedade e cultivo) especialmente a partir dos anos 60-70 (FRITZ; FRITZ FILHO, 2011, p.42).

\footnotetext{
${ }^{10}$ Poderia mesmo afirmar a relevância das biotecnologias como asseverado por Bruno Gasparini, ao citar Rubens Onofre Nodari, que afirma que as biotecnologias estão associadas com múltiplas tecnologias interdisciplinares, não contemplando uma nova ciência, mas ferramentas tecnológicas baseadas em conhecimentos científicos diversificados (2012, n.p.).
} 
Obviamente o protagonismo da Biotecnologia no contexto do combate a fome não é posição unânime. Para alguns ${ }^{11}$ o que se observa é que o investimento na biotecnologia não tem uma proposta humanitária (ou legítima), mas apenas eficácia capitalista. Segundo esse pensamento

“organizações internacionais envolvidas com a definição de regimes e regras internacionais sobre agricultura tendem a privilegiar a agricultura transgênica, alegando que esta é a única solução para resolver a fome no mundo, principalmente para aquelas sociedades tradicionais e mais empobrecidas, desconsiderando os riscos que a adoção desta tecnologia oferece para o meio-ambiente, para a biodiversidade agrícola e para a cultura milenar dos povos. além de negligenciar o fato das pesquisas em agro-biotecnologia estarem concentradas na iniciativa privada, e que a semente em sua versão transgênica não é mais considerada um bem natural, mas uma tecnologia, um código informacional passível de propriedade intelectual." (NIEMEYER, 2009, p.5)

Nesse sentido, se manifesta Maria Laura Silveira que as grandes empresas detentoras de biotecnologia têm como preocupação apenas a expansão e intensificação da produção, acumular ainda mais tecnologia e concentrar mercados consumidores. Essas empresas enfatizam a fome dos países subdesenvolvidos e pobres, mas sem propostas humanistas, apenas "matemáticas" para obtenção de lucros. Para atender interesses puramente mercadológicos há a difusão da ideia de que aumentando a produtividade por meio da biotecnologia seria possível combater a fome no mundo, sendo o principal argumento para a criação de sementes híbridas (GASPARINI, 2012).

Entretanto, com o respeito a esses posicionamentos, há que se reconhecer que a biotecnologia, bem como o desenvolvimento tecnológico como um todo, é um fato inegável e se posicionar contrário, sem uma alternativa palpável, implica em retrocesso. Não se defende, obviamente o desenvolvimento (bio)tecnológico desmedido. Reforça-se que, apenas, como a tecnologia já é parte do cotidiano da sociedade (especialmente

${ }^{11}$ Por exemplo, se posicionam nesse sentido Carolina Burle Niemeyer (2009); Christiane Senhorinha Soares Campos (2007) entre outros. 
ocidental), o que se faz possível (e necessário) é a regulação desse desenvolvimento de modo que não se faça de forma não planejada e desarrazoada. Condenar uma tecnologia ou uma possibilidade biotecnológica em razão de que se insere numa lógica capitalista não parece uma atitude séria. É perfeitamente possível conciliar interesses humanísticos dentro de uma lógica ética de mercado. O Direito Agrário tem se dedicado a conciliar esses interesses no alcance da Justiça Social.

Ainda que exista o discurso motivado por questões mercadológicas, não se pode negar que os avanços biotecnológicos podem sim ampliar a produção, com maior qualidade e com maior capacidade de nutrição. O uso ético desse conhecimento se configura como fundamental para que os Direitos Humanos sejam atendidos, especialmente o direito ao alimento, bem como a observância da dignidade da pessoa humana ${ }^{12}$.

\section{OS RISCOS DE DESASTRES BIOTECNOLÓGICOS}

Como observado, existe uma frenética busca pelo desenvolvimento tecnológico no aprimoramento genético de animais e vegetais, no sentido de potencializar sua produção ${ }^{13}$. Esse conhecimento científico tem avançado a passos largos e esse avanço implica, proporcionalmente, em riscos desconhecidos ${ }^{14}$. O risco de desastres biotecnológicos tem se mostrado cada vez mais presente na sociedade contemporânea. Os avanços na engenharia genética implicam na compreensão e contextualização das informações que são continuamente revisadas. Essa (re)descoberta do conhecimento implica em fugir da estigmatização daquilo que é diferente, mas com atenção aos interesses juridicamente tutelados que não podem ser lesionados. Como destacado por Édis Milaré, a era biotecnológica se inicia, mas “mal esboçada” (2007, p.570)

\footnotetext{
${ }^{12}$ Existe uma características dos direitos humanos chamada "indivisibilidade" que afirma que os direitos humanos são indivisíveis. Nesse sentido há que se ponderar sempre que não existe como atender "grupos" de direitos deixando outros inobservados. Quando se pensa no atendimento de um direito humano, deve-se considerar que todos os direitos sejam simultaneamente respeitados.

13 Não se nega, por certo, o desenvolvimento tecnológico para outros fins, como a cura de doenças, próteses (e órgãos artificiais), prolongamento da expectativa (e da qualidade) de vida etc..

${ }^{14}$ Como observa Anselmo José Spadotto (et all) "não é somente um possível cruzamento entre organismos transgênicos com ou naturais e a metagênese que devem ser consideradas na questão de segurança ambiental. Deve-se ater-se, também, à competição entre as plantas e animais transgênicos contra os seres naturais. Nesse sentido, na natureza, há um equilíbrio entre os seres vivos para o estabelecimento da fundamental biodiversidade. Qualquer forma de vida que não faça parte desse equilíbrio pode representar grande destruição biológica" (2011).
} 
Nessa toada, o Direito deve estar atento aos possíveis impasses que tais novas (bio)tecnologias podem oferecer, onde deve buscar a regulação dos institutos da responsabilidade, da prevenção e da indenização (e quando for possível o restabelecimento do status quo ante).

As aplicações tecnológicas "desencadearam debates acirrados e colocaram em pauta interpelações não só de natureza ética, mas também de ordem científica" o que significa dizer que o "poder da biotecnologia, com seus riscos e oportunidades, é incomensurável e desafiador de vários pontos de vista" (MILARÉ, 2007, p.570).

O sistema jurídico brasileiro, sempre guiado pelos princípios do Direito Agrário (e Ambiental) - destacadamente da função social -, se norteia pelos ditames constitucionais e em respeito aos Direitos Humanos. Considerando-se que as consequências dos produtos geneticamente modificados (transgênicos) ainda são desconhecidas, há uma potencial ocorrência para desastres futuros (para a saúde humana e ecossistemas, por exemplo). Não se pretende, ressalta-se, demonizar a figura da biotecnologia apenas pelo obscurantismo que o futuro pode oferecer, mas unicamente destacar a relevância jurídica e social do debate. O Direito (e inegavelmente o Direito dos Desastres) pode instaurar ou revisar institutos que tutelem direitos e garantias e permitam que os desastres sejam o menos danoso possível.

Por certo, poder-se-ia questionar se há real necessidade do Direito se ocupar desses desastres biotecnológicos, se esses danos não são visíveis (ou objetivamente mensuráveis) em sua maioria (o que pra muitos implicaria em mera especulação ou exercício de "futurologia"). Não se pode negar que os eventos catastróficos especialmente as ligadas à biotecnologia, ainda que seja de probabilidade remota, merecem atenção dos juristas em função das suas consequências catastróficas/danosas. Os bens jurídicos potencialmente atingíveis justificam os esforços em tutelar os processos biotecnológicos possivelmente danosos.

Maria Helena Diniz assevera que os avanços tecnológicos podem trazer ótimos resultados, mas também, podem "colocar em risco o futuro da humanidade, por conter, em si mesmos, os poderes da criação e da destruição da vida dão ensejo à exploração econômica" e ainda "podem gerar resultados esteticamente desastrosos e problemas ético-jurídicos voltados à vida, à morte" (2010, p.460). 
Quando questionado sobre os desastres biotecnológicos, o Prof. D. Délton Winter de Carvalho (uma das maiores autoridades sobre o Direito dos Desastres no Brasil), afirma que os riscos biotecnológicos são

\begin{abstract}
"riscos marcados por uma grande precariedade dos dados científicos quanto as suas probabilidades ou suas consequências, típicos exemplos do desenvolvimento tecnológico recente. Neste sentido, ao mesmo tempo que tais tecnologias trazem a expectativa de benefícios exponenciais, também apresentam sérios riscos, tais como fluxo gênico entre espécies geneticamente alteradas e as espécies nativas, com consequências desconhecidas ao meio ambiente e à saúde humana.
\end{abstract}

Para riscos que envolvem atividades com um forte apelo econômico, expectativa de benefícios, porém dotados de uma precariedade no conhecimento acerca de sua potencialidade lesiva, como é o caso da biotecnologia, destaca-se a necessidade do Direito de impor deveres de monitoramento ambiental ao empreendedor, por meio de controles documentados que devem ser cobrados pelas instituições responsáveis. (CARVALHO, 2014)

Nesse sentido, como se pondera, uma das grandes questões é o que a biotecnologia representa para a sanidade dos indivíduos e da própria espécie humana, sobretudo se afetar a hereditariedade, também no que tange a alimentação (como abordado neste trabalho) se combaterá a fome (endêmica), proporcionará a cura de doenças. De forma que a própria natureza da discussão da biotecnologia somada ao seu recente aparecimento “- fatores estes exacerbados pela rapidez da evolução tecnológica

-, explica uma posição de espera e de cautela adotada pelos cultores da Ética e do Direito" (MILARÉ, 2007, p.572).

Observa-se que a modernidade (ou talvez pós-modernidade) tem imposto situações contraditórias em que a busca por avanços implica na convivência com a nsiedade existencial. Isso proporciona um sentido indivisível a estes riscos, que são fabricados, correspondendo à crescente ação técnico-científica. Os riscos que se 
originam da manipulação genética (possível de gerar mudanças incontroláveis na evolução), destruição de ecossistemas (com perdas maciças da biodiversidade), as toxinas ambientais (contaminação em larga escala e difusão de partículas cancerígenas) e outras formas de desastres biotecnológicos (por exemplo, micróbios modificados poderiam resultar-se em muito difíceis de controlar) são possíveis (VENANZI, 2002, p.134)

Ainda que se conceba esses riscos possíveis, é necessário observar os benefícios que a biotecnologia pode oferecer (como de fato já oferece), pois é um instrumento (como todo conhecimento se propõe) a oferecer possibilidades de melhoria da vida humana. O Direito se incumbe do dever de ponderar esses avanços tecnológicos, os problemas advindos, ainda que se trate de riscos controversos, pois, o desenvolvimento biotecnológico se torna cada vez mais cotidiano.

Seria ingênuo desconsiderar que o desenvolvimento (cujo carro chefe é o desenvolvimento econômico) visa a produção de bens e serviços para mercados consumidores, objetivando lucros. Não se planeja avanços apenas pela ótica humanista, mas sim pelo número de potenciais consumidores/usuários, o que "não é uma estratégia incorreta ou intrinsecamente má” (MILARÉ, 2007, p. 77). Exatamente por essa razão Édis Milaré ressalta que a "composição das legítimas necessidades da espécie humana com as legítimas necessidades do planeta Terra efetiva-se no âmago do processo de desenvolvimento sustentável" (2007, p.81). O Direito Agrário, por suposto, pode identificar e regular no sistema jurídico nacional normas que estejam em sintonia com essa proposta de legitimidade.

\section{A NECESSIDADE DO DESENVOLVIMENTO BIOTECNOLÓGICO SUSTENTÁVEL: CONTRIBUIÇÕES DO DIREITO AGRÁRIO PARA O DIREITO DOS DESASTRES}

Vez que é praticamente um consenso que o medo do futuro e dos resultados incertos dos avanços biotecnológicos não podem ser razões suficientes para interromper o desenvolvimento, há que se ampliar sempre os debates e a compreensão jurídica da questão. Assim já se manifestou Ilya Prigogine: 
“o desenvolvimento científico desemboca então numa autêntica escolha metafísica, trágica, abstrata; 'o homem' deve escolher entre a tentação, tranquilizadora mas irracional, de procurar na natureza a garantia dos valores humanos, a manifestação de uma pertença essencial, e entre a fidelidade a uma racionalidade que o deixa só num mundo mudo e estúpido. (...) A ciência começa a estar em condições de descrever a criatividade da natureza, e o tempo, hoje, é também o tempo que não fala mais de solidão, mas sim da aliança do homem com a natureza que ele descreve" (2002, p.84).

O Direito dos Desastres assim, surge de uma proposta de desenvolvimento sustentável, por buscar o desenvolvimento pautado na ética, na dignidade e na responsabilidade inter e transgeracional. Por certo "reconhece a relação intrínseca entre redução de desastres, desenvolvimento sustentável e erradicação da pobreza" (CAVEDON; VIREIRA, 2012, p.120). Há que se reconhecer, nesse sentido, como um dos principais focos de atuação estatal, visto que a gestão dos desastres deve ser pauta obrigatória da agenda governamental mundial. O Direito dos Desastres também deve levar em consideração a importância da gestão dos riscos, atuando de forma preventiva e planejamento eficiente de estratégias de resiliência (DAMACENO, p.92). Para tanto, o Direito dos Desastres deve se atentar para a diversidade de opiniões e possibilidades, como as que o Direito Agrário pode oferecer, ampliando sua aplicação.

O Direito Agrário é o ramo do conhecimento jurídico intimamente ligado à Reforma Agrária, o que se liga, por sua vez, à soberania alimentar, o trato adequado da terra e dos recursos naturais, a proteção dos camponeses (tanto em sua existência quanto nas relações de trabalho) e a tutela cultural campesina. Também é da seara do ramo jurídico destacado a regulação das ocupações territoriais, a relação com os indígenas e seus conhecimentos tradicionais, comunidades ribeirinhas e todos os demais grupos vulneráveis frente à má administração do conhecimento biotecnológico ${ }^{15}$.

\footnotetext{
15 A legislação brasileira já possui um considerável arcabouço normativo de fiscalização e regulação quanto ao desenvolvimento biotecnológico, ainda que sejam mesmo incipientes os dispositivos dedicados aos desastres biotecnológicos. Não se abordará pormenorizadamente as legislações que tratam do assunto por não ser o foco da proposta que se desdobra em uma perspectiva mais ampla, principiológica e conceitual sobre o assunto. Se constitui um ponto de partida para pesquisa futura em que uma revisão crítica da legislação brasileira será levantada e analisada.
}

Revista de Direito Agrário e Agroambiental | e-ISSN: 2526-0081 | Minas Gerais | v. 1 | n. 2 | p. 91 - 116 | Jul/Dez. 2015. 
A regulação das relações no campo e da produção de alimentos são aspectos do desenvolvimento (sustentável) de um Estado. A valorização do campo (e do Direito Agrário) permitiu que movimentos sociais ligados ao espaço agrário também alcançassem protagonismo nos debates nacionais. Isso possibilitou também um maior destaque para as temáticas de preservação (social, cultural e biológica) dentro das discussões desenvolvimentista. Hoje é possível dizer que o discurso do desenvolvimento meramente econômico (produção com prevalência do lucro) não é mais aceito como coerente - o homem, e não o lucro, é o núcleo do pensamento jurídico contemporâneo. Assim "viver de forma sustentável implica aceitar a imprescindível busca de harmonia com as outras pessoas e com a natureza" (MILARÉ, 2007, p.74).

O Direito Agrário, ao valorizar o protagonismo dos movimentos sociais campesinos, e a valorização do homem do campo - o trabalhador rural, corrobora para o fortalecimento da soberania alimentar (por incentivar o desenvolvimento da agricultura familiar, produção, distribuição, consumo etc.). Um Estado que não tenha o Direito Agrário fortalecido se torna vulnerável, pois seus recursos naturais (e genéticos) se tornam desprotegidos, a aplicação de tecnologias na produção agrícola se faz sem maiores zelos e sem autonomia na produção alimentar. A regulamentação da biotecnologia na produção agrícola deve se dar no sentido de evitar riscos desnecessário, que pode implicar em desastres, bem como retirar a autonomia da produção camponesa se subjugando aos interesses capitalistas de mercado. O Direito Agrário deve proteger (lembremos de sua característica dicotômica) o desenvolvimento e a agricultura familiar, por exemplo.

Assim, a gestão ética dos riscos biotecnológicos dos desastres também deve ser encarado como elemento intrínseco (e implícito) do atendimento da função social da propriedade. Quando a legislação brasileira estabelece como requisitos expressos a adequada utilização dos recursos naturais e a preservação do meio ambiente, bem como o bem-estar dos proprietários e trabalhadores rurais, há que se reconhecer que há aqui uma reserva implícita de observância quanto aos desastres biotecnológicos. Ora, os desastres biotecnológicos incorrem em prejuízos à preservação do meio ambiente, que pode sofrer danos irreversíveis, bem como a segurança e bem-estar dos proprietários e trabalhadores rurais estariam igualmente comprometidos. Obviamente o aproveitamento racional e adequado da propriedade e a observância das disposições que regulam as relações de trabalho, também implicam também nessas mesmas conclusões. A função 
social deve ser compreendida como um todo, incluindo a gestão dos desastres biotecnológicos (potencial e altamente danosos).

A meu ver, o problema mais grave no que diz respeito à biotecnologia na legislação brasileira (em especial a Lei n. 11.105/2005) é que esta atribui exclusivamente a um órgão eminentemente técnico e político (CTNBio) a análise de se uma determinada pesquisa ou atividade deve se submeter a um processo de licenciamento ambiental. Assim, a legislação específica acaba bloqueando o controle ambiental de tais técnicas, uma vez que a CTNBio tem um perfil eminentemente pró-biotecnologia. Este bloqueio normativo da biotecnologia ao controle imediato dos órgãos ambientais parece-me, no mínimo, inconstitucional. (CARVALHO, 2014)

Quando o Direito Agrário oferece tais parâmetros deve-se observar que a abrangência de tutela incorpora todas as dimensões dos Direitos Humanos "o que significa, em outras palavras, a busca da PAZ” (MARQUES, 2012, p.40). A função social, bem como a ideia da busca da Justiça Social, existe em função da busca pela dignidade da pessoa humana, norteando as relações do desenvolvimento. A CRFB/88 oferece princípios basilares que também corroboram para a pertinência da tutela dos desastres biotecnológicos, garantindo o desenvolvimento sustentável e apartando as técnicas atentatórias e predatórias (COUTO; KRAWCZUN, 2015, p.4).

Pode-se observar que o Direito Agrário, nesse aspecto, é palco para a aplicação de vários direitos hoje elencados como sendo de quarta dimensão, somando-se à todas as outras que também são caros aos debates jus-agraristas ${ }^{16}$.

\footnotetext{
${ }^{16}$ Comumente se indica a existência (quase) inconteste de três dimensões de Direitos Humanos: I- a primeira, que versa sobre as liberdades públicas, direitos individuais, como uma abstenção por parte do Estado; II- a segunda, que versa sobre direitos coletivos, econômicos e culturais, especialmente versando sobre a não intervenção estatal na economia; e, III- a terceira, que trata de direitos sociais, exigindo uma atitude proativa do Estado. Ainda podemos mencionar a existência de uma quarta dimensão de direitos humanos, que tratam especificamente sobre os direitos relacionados ao desenvolvimento da biotecnologia (sua regulação, limitação, entre outros). Chega-se a mencionar que existe a quinta dimensão de Direitos Humanos (que versaria sobre o Direito à PAZ, por exemplo). Todos, é preciso que se destaque, estão de forma direta e indireta, presentes nos debates do Direito Agrário.
} 


\section{CONSIDERAÇÕES FINAIS}

A modernidade trouxe consigo avanços científicos e tecnológicos que, paulatinamente se tornaram presente no cotidiano da sociedade. As conquistas nessas novas tecnologias não tem perspectiva de redução, mas, ao contrário, procura acelerar o alcance de novos horizontes. Assim, o novo papel do Estado é, frente aos contornos atuais da globalização, impedir que o capital (que circula cada vez mais livre, maximizando seu processo de acumulação) desmantele a lógica do interesse o interesse público para convertê-lo apenas em um agente financiador de investimentos privados (técnico-científicos, por exemplo) sob a justificativa de desenvolvimento (CAMPOS; CAMPOS, 2007, n.p $)^{17}$.

O Estado Brasileiro, assim como os demais, deve buscar da segurança e da soberania alimentar, mas não fazê-lo apenas sob o ponto de vista mercadológico, e sim pautado em Direitos Humanos e princípios reguladores das normas jurídicas e das políticas públicas. Nesse aspecto em particular o Direito Agrário converge como fonte de princípios estruturantes para esse agir ético do Estado.

Os avanços biotecnológicos são uma realidade cada vez mais presente, mas nem por isso mais acessíveis do ponto de vista jurídico-científico. Existem "senões" ainda a serem ponderados sobre os resultados e consequências que o desenvolvimento das descobertas biotecnológicas podem trazer ao planeta. Os danos possíveis em médio e longo prazo não são de todo conhecidos, e muito se especula sobre as dimensões que podem tomar. Ainda com essas incertezas produtos geneticamente modificados já estão presentes no consumo, ainda sem a devida discussão sobre o assunto. A presença desses produtos resultados do conhecimento biotecnológicos pode, em uma visão potencial, resultar em desastres que, por sua vez, representarão prejuízos incomensuráveis para a vida humana e natural do planeta. Esse risco é tão possível quanto imprevisível, e, por isso mesmo, há uma dificuldade em trazer esse debate para o universo jurídico que busca maior objetividade. O risco, quando possui resultados potencialmente danosos,

17 "E, ao que parece, o novo papel do Estado, atribuído pelos que tem poder de decisão na atual correlação de forças mundial, tende a se caracterizar pela ausência de uma política territorial vinculada a um projeto nacional. $\mathrm{O}$ resultado é que o capital fica cada vez mais livre para determinar os usos do território-mundo, de modo a maximizar seu processo de acumulação em escala global. A lógica privatista, que inclui o desmantelamento de serviços públicos como saúde, educação e previdência, para diminuir gastos sociais do Estado e a intensificação do papel do Estado como agente financiador de grandes investimentos privados (industriais, técnico-científicos e de infra-estrutura) são fortes indícios dessa tendência. Por isso quando se fala de estado mínimo é preciso questionar sempre: mínimo para quê e para quem?" (CAMPOS; CAMPOS, 2007, n.p) 
merece atenção inclusive e especialmente para ser evitado ou, quando não for possível, minimizar as consequências com a atribuição das devidas responsabilidades.

O Direito dos Desastres surge, especialmente se dialogado com o Direito Agrário (e o Direito Ambiental de quem é também fruto), como espaço profícuo para debater a atuação estatal na fiscalização e gestão do desenvolvimento biotecnológico com destacada atenção para suas consequências potencialmente danosas. Assim, os Direitos Humanos são observados, centralizando os interesses da sociedade e não interesses puramente econômicos na gestão dessas novas (bio)tecnologias. A Justiça Social se fará efetiva, como busca o Direito Agrário, com o equilíbrio entre desenvolvimento humano e econômico, ou seja, com o aperfeiçoamento das técnicas de gestão e aplicação do capital e a dignidade da pessoa humana.

Toda a discussão acerca do Direito dos Desastres aplicado aos desastres biotecnológicos se mostra limitada. Um fator é o desenvolvimento célere da biotecnologia que traz aspectos ainda não amadurecidos, especialmente para o Direito, e que demandam de uma análise cada vez mais inter e transdisciplinar. Contexto este que se faz cada vez mais urgente com a valorização do conhecimento científico biotecnológico no séc. XXI, que ainda não mereceu a atenção devida dos juristas. A participação do Estado nesse processo, no sentido de barrar, minimizar, incentivar, permitir, financiar e punir depende de uma visão jurídica amadurecida da questão, que deve se afastar do mero medo do progresso, mas também não pode ensejar na leviana crença que não se corre riscos.

O Direito, assim, possui mecanismos para um agir ético por parte dos cientistas e pessoas ligadas aos projetos de desenvolvimento biotecnológico, prevendo e impondo responsabilidades devidas, construindo um agir ético e sustentável. Há muitos direitos e garantias envolvidos quando um novo conhecimento é gerado, ele também traz consigo um novo horizonte desconhecido e que precisa ser cautelosamente analisado. A imposição de limites não tem o condão de impedir os avanços, mas apenas de controlar, na medida do possível, as consequências. Poder-se-ia dizer que garante-se o direito ao desenvolvimento, desde que atenda à sua função social (parafraseando a CRFB/88), que atenda aos ditames da ética e da sustentabilidade. Não se pode comprometer (talvez) a própria existência da vida na Terra pelo enriquecimento de determinados grupos. 
Não se constitui interesse do presente estudo negar os benefícios da biotecnologia para questões como a segurança alimentar ou a soberania alimentar (ou mesmo para a saúde humana), mas formular questionamentos que precisam ser analisados pela comunidade jurídica e reformulados como normas e políticas públicas. É preciso publicizar os debates sobre o Direito Agrário e sobre o Direito dos Desastres, como aspectos presentes na sociedade e na realidade brasileira (quiçá mundial), fomentando uma visão crítica e receptiva para esses avanços.

É preciso refletir sobre as repercussões que tais biotecnologias têm e terão nas gerações futuras, bem como refletir sobre qual é o papel do Direito (e sua responsabilidade nesse processo). Os desastres naturais já acontecem e são noticiados, os desastres biotecnológicos já se constituem como resultado da (ir)responsabilidade humana, evitáveis portanto. A valorização do Direito Agrário é parte importante desse processo, pois tutela o espaço agrário como dimensão em que o natural e o humano dialogam e interagem com maior intensidade. O Direito dos Desastres, fortalecido por tais debates interdisciplinares se potencializa como ramo do Direito fortalecido e avançado para acompanhar as mudanças (e o riscos) que o conhecimento nascente podem oferecer.

\section{REFERÊNCIAS}

BORGES, Paulo Torminn. Institutos básicos do direito agrário. São Paulo: Saraiva, 1987.

CAMPOS, Christiane Senhorinha Soares. Campesinato autônomo - uma nova tendência gestada pelos movimentos sociais do campo. Revista Lutas \& Resistências, número 1, pg. 146-162, UEL/Gepal, Londrina, setembro de 2006.

CAMPOS, Christiane Senhorinha Soares; CAMPOS, Rosana Soares. Soberania Alimentar como alternativa ao agronegócio no Brasil. Scripta Nova (Barcelona), v. Vol. X, p. n.245 (68), 2007. Disponível em: http://www.ub.edu/geocrit/sn/sn-24568.htm Acesso em 22 de jul de 2015.

CARVALHO, Délton Winter de. Direito Ambiental e a gestão de desastres naturais. [18 de março de 2014]. São Leopoldo/RS. Instituto Humanistas Unisinos. Entrevista concedida a IHU. Disponível em: http://www.ihu.unisinos.br/entrevistas/529319- 
direito-ambiental-e-a-gestao-de-desastres-naturais-entrevista-especial-com-deltonwinter-de-carvalho. Acesso: 07 de jul. 2015.

CAVEDON, Fernanda de Salles; VIEIRA, Ricardo Stanziola. Conexões entre desastres ecológicos, vulnerabilidade ambiental e Direitos Humanos: novas perspectivas. Revista Internacional de Direito e Cidadania, n.13, p.117-130, jun/2012.

CONCEICAO, L. C.; Freitas, André Luis Pereira de; SANTANA, André Ribeiro de; NAKAYAMA, Luiza . As origens simbólicas da Educação Ambiental. Educação Ambiental em Ação, v. 34, p. 34, 2010. Disponível em: http://www.revistaea.org/artigo.php?idartigo $=923$

COUTO, Clayton Santos do.; KRAWCZUN, Natália Branco Lopes. Biodireito e dignidade da pessoa humana: limites e possibilidades. 2015. Disponível em: < http://www.faatensino.com.br/wp-content/uploads/2015/07/PROJETO-BIODIREITOFAAT.pdf>

CRED, Center for Research on Epidemiology of Disasters. Annual Disaster Statistical Review, 2012.

DAMACENA, Fernanda Dalla Libera. A formação sistêmica de um direito dos desastres. Dissertação (mestrado) 152f. - Universidade do Vale do Rio dos Sinos, Programa de Pós-Graduação em Direito, São Leopoldo-RS, 2012.

DINIZ, Maria Helena. O estado atual do biodireito. - ver. aum. E atual. - São Paulo: Saraiva, 2010.

FONTES, Joaquim Brasil. Erysichtonis ora profani. No crisol das formas mutáveis. Letras Clássicas, n.9, p.181-214, 2005. Disponível em http://www.revistas.fflch.usp.br/letrasclassicas/article/viewFile/722/627

FRITZ, Karen Beltrame Becker; FRITZ FILHO, Luiz Fernando. A INSEGURANÇA ALIMENTAR NO RIO GRANDE DO SUL: uma análise comparativa entre o rural e o urbano. In: Elenise F. Schonardie. (Org.). Ambiente e Justiça Ambiental:Ambiente e Justiça Ambiental. 1ed.UNIJUI: Editora Unijuí, 2011, v. 1, p. 36-78. 
GASPARINI, Bruno. Biotecnologia e Direitos Humanos. Observatório E-Gov. 2012. Disponível em http://www.egov.ufsc.br/portal/conteudo/biotecnologia-e-direitoshumanos Acesso em 15 de jul.2015.

MARQUES, Benedito Ferreira. Direito agrário brasileiro. 10 ed. rev.e ampl. São Paulo: Atlas, 2012.

MILARÉ, Édis. Direito do ambiente: doutrina, jurisprudência, glossário. 5 ed. ref., atual. e ampl. São Paulo: Editora Revista dos Tribunais, 2007.

MORUZZI MARQUES, Paulo Eduardo. Embates em torno da segurança e soberania alimentar: estudo de perspectivas. Segurança Alimentar e Nutricional, v. 17, p. 78-87, 2010.

NIEMEYER, Carolina Burle. Soberania alimentar: a resposta camponesa à agricultura transgênica. 2009. Trabalho apresentado ao XII Conferência Anual da Associação Internacional para o Realismo Crítico, Rio de Janeiro (RJ). 2009.

OCTAVIANO, Carolina. Muito além da tecnologia: os impactos da Revolução Verde. ComCiência, Campinas, n. 120, $2010 \quad$. Disponível em $<$ http://comciencia.scielo.br/scielo.php?script=sci_arttext\&pid=S1519$76542010000600006 \& \operatorname{lng}=$ pt\&nrm=iso $>$. acessos em 24 ago. 2015.

PENNA, João Bosco; CANOLA, Bruno César. A evolução da biotecnologia e da engenharia genética frente às implicações ambientais, ao biodireito e aos direitos fundamentais. Revista da Faculdade de Direito da UFG, v.33, n.2, p. 74-88, jul./dez. 2009.

PRIGOGINE, Ilya. As leis do caos. Tradução Roberto Leal Ferreira. São Paulo. Unesp. 2002.

SANTOS, Maurício Duarte. Análise Contemporânea sobre a relação entre Direito Ambiental e Desastres com Efeitos Transfronteiriços. In: CAMPELLO, Livia Gaigher Bosio; MOROMIZATO, Consuelo Yatsuda; CAVALLAZZI, Rosangela Lunardelli. (Org.). Direito Ambiental. 1ed.João Pessoa: CONPEDI/UFPB, 2014, v. III, p. 349364. 
SILVA, Romeu Faria Thomé da. Manual de direito ambiental. Salvador: Jus Podvm, 2014.

SODERO, Fernando Pereira. Direito agrário e reforma agrária. São Paulo: Leg. Brasileira, 1968.

SPADOTTO, Anselmo Jose; GUERRINI, Ivan Amaral et al. Alimentos transgênicos: interface jurídico-agroambiental. Revista Jus Navigandi, Teresina, ano 16, n. 2817, 19 mar. 2011. Disponível em: <http://jus.com.br/artigos/18711>. Acesso em: 15 ago. 2015.

TABAK, Bernardo. Ministério Público Federal recomenda paralisação da construção de Angra III. G1, Rio de Janeiro, 24/06/2010. Disponível em: < http://g1.globo.com/riode-janeiro/noticia/2010/06/mpf-recomenda-paralisacao-da-construcao-de-angraiii.html> Acesso em 15.06.2015.

VENANZI, Augusto de. Globalización y corporación: el orden social en el siglo XXI. Anthropos Editorial. Caracas. 2002.

VICENTE, Laura Lícia de Mendonça. A revolução biotecnológica do século XXI. Reflexões éticas e jurídicas. Revista Jus Navigandi, Teresina, ano 16, n. 2855, 26 abr. 2011. Disponível em: <http://jus.com.br/artigos/18976>. Acesso em: 16 ago. 2015. 